Article

\title{
The Effect of Incremental Innovation and Switching-Over to Architectural Innovation on the Sustainable Performance of Firms: The Case of the NAND Flash Memory Industry
}

\author{
Heiseung Kim, Changhyun Park and Heesang Lee * \\ Graduate School of Management of Technology, Sungkyunkwan University, Chunchundong 300, \\ Suwon 440-746, Korea; kim2753@skku.edu (H.K.); pchrgc@skku.edu (C.P.) \\ * Correspondence: leehee@skku.edu; Tel.: +82-31-290-7604
}

Received: 28 October 2019; Accepted: 10 December 2019; Published: 11 December 2019

check for updates

\begin{abstract}
This paper presents an empirical study that shows the relationship between innovation activities and the sustainable performance of firms in terms of market share and profit. While previous studies of innovation effects have focused on one type of innovation in the industry, such as incremental or radical innovations, the study of both incremental and architectural innovations in the same industry would enrich our understanding of innovation. This study discusses and emphasizes the importance of continuous incremental innovation and how switching-over to architectural innovation affects the sustainable performance of firms in the NAND flash memory industry. A systematic content analysis, comparing the changes in market and profit leadership in terms of continuous incremental innovation and an introduction of architectural innovation, was performed, and it was concluded that both continuous incremental innovation and switching-over to architectural innovation positively affects the sustainable market and profit leadership of firms. Additionally, architectural innovation reframes the technological lifecycle in the industry and gives a firm a chance to retain and continue its technological leadership by establishing new dominant designs. This study suggests that continuous incremental innovation is very important for high-tech firms, and firms should consider the option of switching-over to architectural innovation instead of the incremental development of current dominant design when the complexity of technology and market is increased in order to have a sustainable advantage.
\end{abstract}

Keywords: continuous incremental innovation; architectural innovation; design change; profit; market share; sustainability; NAND flash

\section{Introduction}

A firm's sustainable performance is an important issue for its survival in the market. While a firm's innovative behavior is generally correlated with improved financial performance [1,2], research associating types of innovation with a firm's sustainable performance is still limited. This study focuses on the high-tech industry, in which technological innovation is important to sustain market leadership along with sustainable performance. The flash memory industry is a good example to observe the causality between technological innovation and the firms' sustainable performance.

Flash memory, the largest non-volatile memory type in the semiconductor market, was introduced by Toshiba in 1984 [3]. After this introduction, Intel and Toshiba were able to commercialize the NOR (NOT OR) type flash in 1988 and the NAND (NOT AND) type flash in 1989, respectively [3,4]. The main differences between the NOR and NAND flash memories are architectural structure because the NOR provides parallel access and the NAND provides sequential access of data. Since the NOR flash 
memory is used for the random access of data, it is faster than the NAND flash memory because it provides sequential access to data. However, the structure of the NAND flash is simpler than that of the NOR flash, so it is more convenient and inexpensive to increase its density. Therefore, the NAND type flash is used for the storage of data, and the NOR flash is used for the storage of codes in general [3]; eventually, the NAND flash dominated the flash industry.

Since the inception of the flash memory market in the 1980s, the NOR flash memory has been the dominant design and it accounted for $91 \%$ of total flash memory revenue in 2000 . However, in 2005, NAND flash revenue surpassed that of the NOR flash for the first time due to the emergence of mobile electronics such as cell phones, MP3 players, memory cards and digital cameras. Since then, the NAND flash market has grown significantly, accounting for 53.8 billion USD in sales in 2017 [5]. In 2013, Samsung was able to successfully introduce a Vertical NAND (VNAND) flash to the market in order to overcome scaling issues and tried to lead the architectural innovation by changing the dimensional design of NAND flash technology from 2D to 3D. Competitors followed the development of the VNAND flash memory and the VNAND flash market was expected to exceed the planar NAND flash market in 2017 [5]. The history and characteristics of the dominant design in the flash memory industry are summarized in Figure 1. As shown in Figure 1, NOR flash has a different architecture than planar NAND and VNAND. The dominant design changed because of the increase in data storage applications. The characteristics of planar NAND and VNAND are very similar, except for their architectural differences in developing a next-generation product, which changed from planar scaling to 3D stacking in order to constantly improve density and cost. Hence, the flash industry overcame the main obstacles of technological innovation through changes in the characteristics of its dominant architectural design.

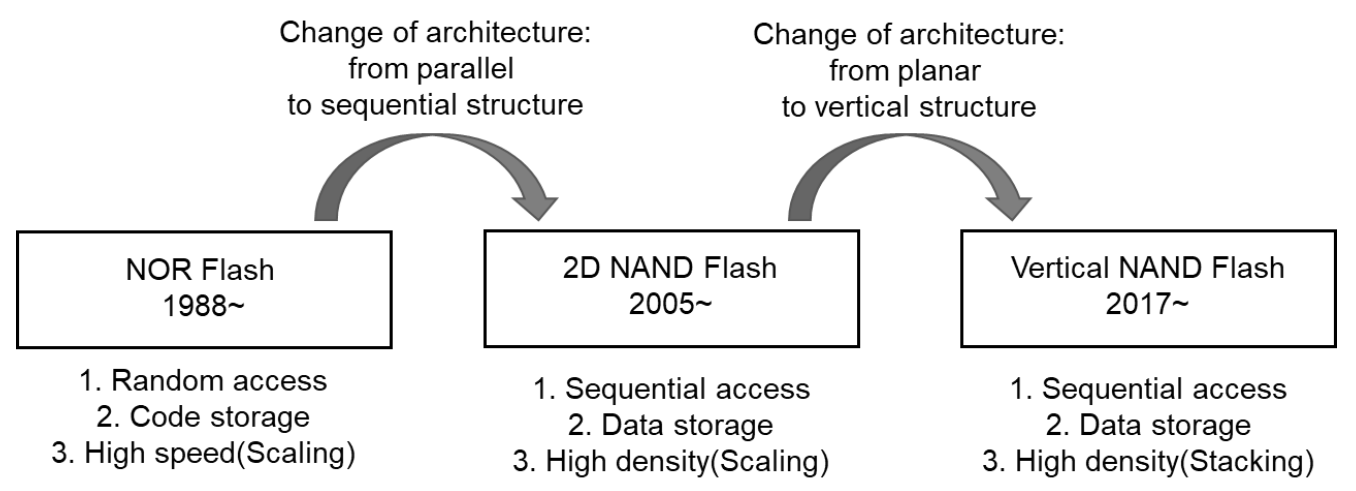

Figure 1. History and characteristics of dominant design changes in the flash industry.

The NAND flash memory industry was selected for this study because of its critical industry characteristics; the NAND flash has a short product lifecycle and is both technology-driven, and equipment based [6]. The average product lifecycle of a NAND flash is about two to three years, and this short lifecycle implies that the flash memory company with technological leadership must be able to gain higher profit than its initial investment [7]. On the other hand, technological followers may suffer from a reduction of the product's price because of the mature state of a short product lifecycle when a new product is introduced into the market. Technological followers might also find it extremely difficult to regain their initial investment since the NAND flash memory industry is driven by advanced scaling node technology [8]. For the production of NAND flash memory, extremely expensive equipment with numerous processing steps is also required, since a new semiconductor fabrication plant costs billions of dollars. Therefore, a proper strategy to develop new products is needed to stay competitive in the industry while competing with rival companies. These industry characteristics make firms from other industries hesitant to enter the NAND flash business; the initial investment is huge, and it is very hard to catch up to the main four companies: Samsung, Toshiba, Micron, and SK Hynix. 
This study focuses on the period from planar NAND to VNAND, which are the second and third stages of Figure 1, respectively. The characteristics of the NAND flash market make it an interesting candidate to investigate how the relationship between innovation activities in the high-tech industry affects the sustainable performance of firms. The objective of this study is to investigate the effect of continuous incremental innovation and the switch-over to architectural innovation in the NAND industry. This study also tries to confirm whether the NAND flash memory industry has similar results to the DRAM industry, where continuous scaling is important for the sustainable performance of firms. To do so, this study reviews the extant literature in terms of innovation types, dominant design changes, and the relationship between market/technology leadership and firm performance in Section 2. Then, this study presents findings from the NAND flash industry and discusses whether there is any other phenomenon that has been affected by the introduction of architectural innovation from planar scaling to vertical stacking in the NAND flash industry.

\section{Theoretical Background}

\subsection{Innovation Types}

As Freeman mentioned, the ability to engage in successful technological innovation is the main factor for competitive advantage [9]. Consequently, many companies are conducting numerous studies to remain competitive in the industry [9]. A company's ability to introduce new products and processes and to introduce them in shorter periods of time is crucial; this ability has become one of the most important competitive tools for firms [10].

There have been studies on several different innovation classifications [11-15]. However, some classifications include non-technological innovations such as market, organizational, and environmental capabilities [13-15]. In order to effectively organize technological innovation activities, we use the work by Henderson and colleagues (1990), which divides technological innovation types into four categories: incremental, architectural, modular, and radical [11].

- Incremental innovation: Innovation that does not change the architecture and concept; however, improvements to cost and performance are achieved through innovation.

- Architectural innovation: Innovation via a change in architecture; however, this innovation does not change the product's concept.

- Modular innovation: The technological concept is fundamentally changed; however, it does not change the product's architecture.

- Radical innovation: Disruptive innovation with a new architecture and concept.

Table 1 summarizes the innovation activities in the memory industry, which are used in our research by adopting Henderson's definition of innovation types. For incremental innovation, changes include activities such as using more efficient or less expensive materials and continuous scaling to the next nodes to reduce cost. Architectural innovation includes the structural change of device to provide parallel access to sequential access and architectural design change of NAND flash from planar scaling to vertical stacking. Modular innovation includes the development of resistivity based memories such as MRAM (magnetic), ReRAM (resistive), and PRAM (phase change), which are being developed to replace current electron-based memory devices. Finally, an example of radical innovation is the development of non-silicon based memory such as neuro-morphic memory or other types, which involves radical changes in both architecture and concept. 
Table 1. Innovation activities in the NAND flash industry (created from [16]).

\begin{tabular}{cc}
\hline Types & Activities \\
\hline Incremental Innovation & $\begin{array}{c}\text { Cost decreases/changing material or layout } \\
\text { Scaling (shrinkage of NAND flash device to the next node) }\end{array}$ \\
\hline Architectural Innovation & $\begin{array}{c}\text { Architectural change due to parallel to sequential access structure } \\
\text { Design change from a planar to a vertical structure }\end{array}$ \\
\hline Modular Innovation & Development of MRAM, PRAM, ReRAM \\
\hline Radical Innovation & Development of non-silicon based memory \\
\hline
\end{tabular}

Previous research has tried to expand the type of innovation and combine it with other concepts such as complementary technology and sustainability [17,18]. Roy and Miller used the case of the image sensor industry to extend the innovation types by Henderson and Clark and concluded that complementary technologies are important to overcome technological trade-offs on product innovations [18]. For our study, since complementary technologies such as equipment, processes, and materials are already counted in products developed through scaling, we will adopt the concept of the technological and market complexity framework by Seebode et al. (2014) [17]. This framework discusses the type of innovation and complexity of technology and the market. Incremental or radical innovation is the output of exploited or bounded exploration, respectively. The complexity arising out of technology and the market leads to difficulty in predicting the current state of technology and market due to the increasing number of possible states of this environmental situation. This leads to incremental innovation to reconfigure and reframe the existing ones to reduce the complexity. Also, for radical innovation, it would require the development of new ways, modifying or even abandoning the current technology, which could let new entrants enter the system and co-evolve together. Therefore, the complexity of technology and the market pushes firms to learn new technological frames and "unlearn" the old and established technological frame. According to this concept, Figure 2 shows sustainable innovation in the flash industry. For the flash industry, NOR has been the dominant design for a long time; therefore, the technological frame is already established. However, after 2000, due to the emergence of mobile devices, there was an increase in market complexity in the NAND industry. Therefore, NAND flash received attention and was reframed (movement to the right) and eventually became the dominant design of the flash industry (movement to the top left), then the continuous innovation of NAND flash scaling was performed as a dominant design. From 2008 to 2012, the technology and market complexity increased considerably due to the chicken game (which is discussed in Section 2.3). After 2013, architectural innovation of VNAND was introduced (movement to the right) and also eventually became the dominant design (movement to the top left). Currently, NAND flash manufacturers are continuously increasing the number of stacks for VNAND. For constant development of a currently established dominant design, the activity of the firm moves to the left side of the chart. However, when a complexity of technology and the market increases, then the innovation is reframed and moves to the right side of the chart, which has a probability of eventually become the dominant architecture [17]. Then the dominant architecture moves to the left again for continuous incremental innovation until new architecture is introduced to reframe the innovation activities in the industry. 


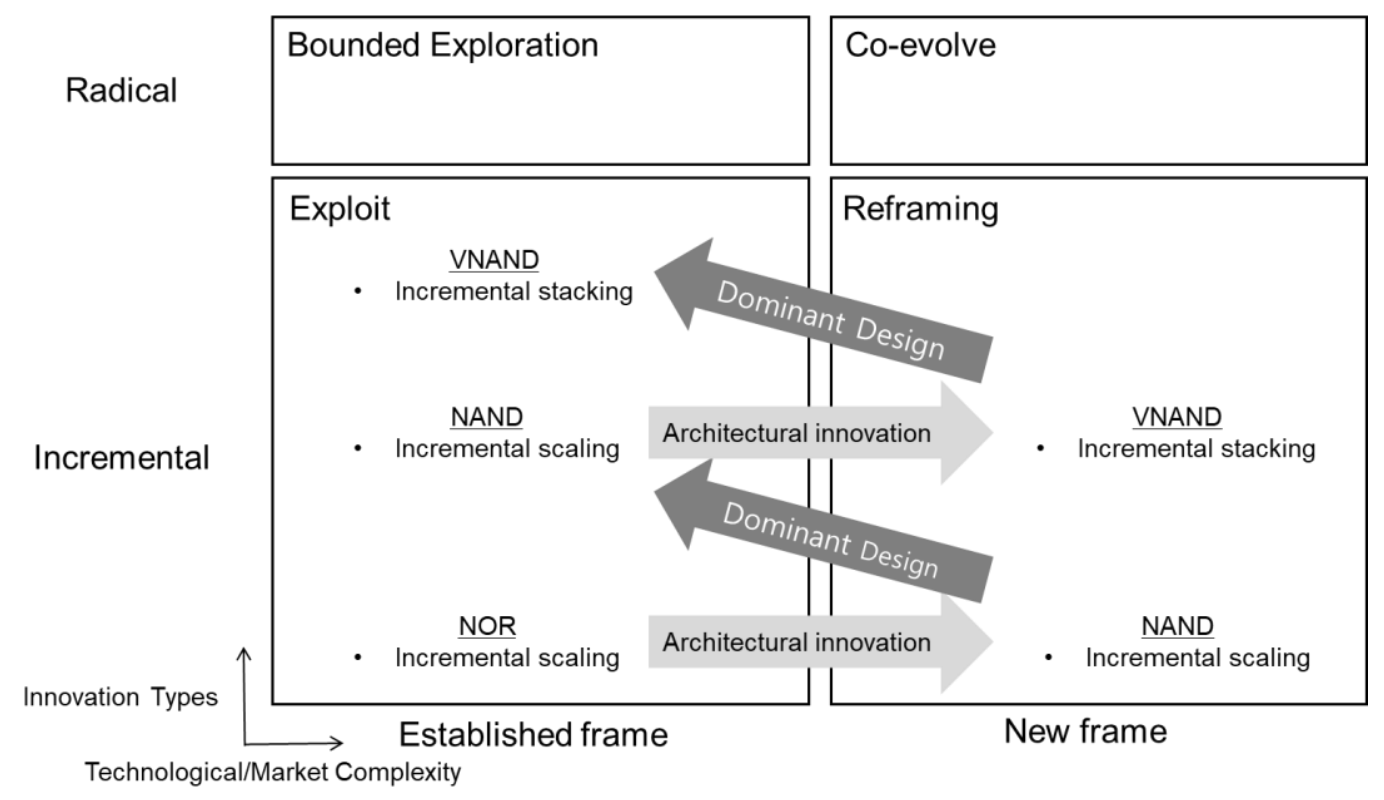

Figure 2. Sustainable innovation in the flash industry (created from [17]).

In terms of benefits from innovation, extant research has focused more on incremental and radical innovation types, including new product development [19-26]. The research focus on incremental innovation might be due to the fact that incremental innovation is used extensively and is easily attempted in the industry. Moreover, radical innovation has been studied extensively due to the fact that it is expected to affect firms significantly in terms of new product development and making a product successful. The study of resource allocation on a firm's innovation activities shows that many companies allocate most of their resources and R\&D expenses to incremental innovation, even though the financial effects of incremental innovation are hard to predict [27].

Scaling, which is one of the best-known examples of continuous innovation in the memory industry, is also the most important innovation activity in the NAND flash memory industry [28]. However, little research has been carried out on the benefits of successful continuous innovation for firms. Kim and Lee (2017) argued that, in the DRAM industry, continuous scaling positively affects firm performance [16]. Interestingly, in the NAND flash industry, even though continuous scaling innovation is getting harder, many companies have tried to reduce costs and to increase performance by doing so. However, the introduction of architectural innovation of different designs, such as a dimensional change from planar to vertical architectures, gave the firms a chance to restart and successfully continue the reduction of cost and improvement of performance. Therefore, an empirical study of continuous incremental innovation and the switch-over to architectural innovation from planar to vertical in the NAND flash industry would enrich our understanding of the benefits of continuous incremental innovation and architectural innovation.

\subsection{Dominant Design}

The terminology of the dominant design was introduced by Utterback and Abernathy (1975), who defined a dominant design as the particular product design that is accepted as the standard for its product category or the whole industry in the market [29]. When a new technology emerges, firms introduce a number of different technological designs, which can add similar functionality to a product [30]. Different designs will compete among themselves, and, ultimately, the technology that can be referred to as the "industry standard" will be established.

Researchers have emphasized the importance of dominant design; many studies in this research area have focused specifically on the influence of dominant design in a firm's innovation performance. Previous research has argued that dominant design hinders innovation [31] or negatively influences 
innovation by increasing the competitor's production cost, increasing the concentration of the market, increasing their monopoly power and reducing product choice, with the possibility for premature technology selection [32] and also strong intellectual property rights [33]. On the other hand, other researchers have reported that a dominant design can enhance innovation. Blind (2013) stated that a dominant design avoids a "lock-in into old technologies" and, therefore, positively influences innovation activities [34]. Additionally, Swan (2000) and Soh (2010) concluded that the existing dominant design would increase an individual firm's innovative performance [32,35].

In the memory industry, dominant designs do not emerge frequently. For example, the DRAM industry used the same dominant design for about 50 years to enhance performance. Firms develop the same dominant design using planar scaling. On the other hand, efforts to replace the current dominant design by changing the design of the product's structure have only been attempted in the NAND industry. In this study, we define architectural design change as an innovation of a product's structure, which gives the firm a chance to develop new designs and enhance the performance of the product [36]. Note that we include architectural design change as one form of architectural innovation in the NAND flash industry, as seen in Table 1. There are several studies on architectural innovation at the industry level. However, a study of dimensional architectural innovation by design change has not been conducted [11,12]. Therefore, it is important to investigate how new architectural design changes affect the firms' sustainable performance in the NAND flash memory industry.

\subsection{Relationship of Market Leadership and Profit}

For the majority of firms, including NAND flash manufacturers, retaining leadership in the industry is a major business goal since firms are able to continuously gain the benefits of being a leader as long as they can sustain being at the top of the market [37]. Previous studies have shown diverse conclusions on the relationship between leadership and firm performance. However, these studies did not consider firm size to be a factor and included both small and large firms [38-40]. For large firms only, Boone and colleagues (2007) observed that the forces of competition were more significant, and the performance relationship between competing firms was easier to observe [41].

For the NAND flash industry, which comprises very large-sized firms, the competition is more intense and significant; therefore, technological innovation is very important in order to compete against other firms and sustain market leadership. During the period of our study, from 2008 to 2012, there was a so-called "chicken game", a brutal battle where the memory manufacturers lowered the prices below production costs to make one of their competitors to run out of business. In 2012, one of the large DRAM manufacturers, Elpida, ran out of business due to the game of "chicken". Since then, the fear of memory manufacturers has been great and they do their best to reduce cost. Even though the semiconductor market is highly depended on the market situation, the profitability is mainly determined by the innovation activity of scaling [42,43]. The total cost improvement of a semiconductor device is from $25 \%$ to $30 \%$ every year-feature size reduction, the output of scaling, counts for about half of the cost improvement and all other improvements including equipment and materials improvement counts for another half of the cost improvement; yield improvements, which counts for only $1 \%$ [43]. Since most of the equipment productivity and material performance does not depend on the development of NAND flash manufacturers but the equipment and material companies, a major effective innovation to reduce cost and improve the profitability for the NAND flash manufacturers is the efficiency of NAND flash fabrication [43]. That is why most of the firms in the memory industry try to develop next-generation products through continuous scaling or stacking for the VNAND.

There is also a study on the innovations of the market leader in the semiconductor industry. Weber and Yang (2014) studied 29 cases of semiconductor manufacturing and supply firms and concluded that rapid manufacturing is important to improve the performance of a firm [44]. They concluded that leading-edge manufacturers (LEMs), usually market leaders or technology pioneers, could earn a greater profit than fast followers. However, this study included both small and large semiconductor 
firms and also included semiconductor design firms; therefore, it is difficult to determine the effects of technological innovation on the performance of the leading firm in the memory industry, since the memory industry market is oligopolistic, and its firms are large in size. Therefore, a study of market leaders and their followers in the NAND flash industry would enhance our understanding of industries with large firms where the forces of competition are high.

Numerous firms are trying to improve their performance by developing innovative products; therefore, a study to investigate the relationship between innovation and organizational performance has been conducted [45]. Also, the previous research on continuous innovation supports the idea that continuous innovation helps firms achieve competitive advantage and positively affects firms' performance [46,47]. Researchers have argued that the RBV (resource-based view) and DCV (dynamic-capabilities view) theories are able to explain the resources and capabilities that enable a firm to continuously innovate $[48,49]$. However, the RBV theory only describes a case of a static nature [50]. Therefore for a highly dynamic industry, such as the NAND flash industry, the DCV theory is more suitable to investigate the relationship between the act of continuous innovation and a firm's performance since the DCV places a high emphasis on a firm's ability to integrate, establish, and reconfigure their competencies to perform continuous innovation [51]. The act of continuous innovation would help the firms achieve higher performance and be able to attain sustainability in the market. Recently, Bowen and colleagues (2010) used meta-analytic tests and were able to conclude that a firm's innovation and future performance are positively related [52]. Additionally, Kim and Lee (2017) presented an empirical study of the DRAM industry, which possesses very similar characteristics to the NAND flash industry, and concluded that continuous scaling would affect the firms' performance positively and also suggested that it would increase the firms' chances of survival [16]. However, there is a lack of research on this matter, which suggests that the effect of innovative activities when the complexity of technology and market is getting larger, and the previously established innovation activities have reached a limit.

In order to maintain leadership, the ability to continuously innovate new products and processes in a short time period is critical for a firm's survival and has become a major competitive tool [10]. Van Valen (1973) presented a theory commonly known as the "Red Queen effect". This theory introduces the concept that competition will remove less sustainable organizations from the industry and encourage organizational learning to ensure survival, and firms gain a competitive advantage when pitted against ever-evolving opposing firms in a constantly changing environment [53]. Therefore, innovation continuity is important for achieving sustainability and remaining competitive in a constantly changing environment [16,54]. This theory, which mostly describes high-tech companies, explains the continuous race between firms where front-running innovation can increase a firm's competitiveness while simultaneously decreasing its competitors' competitiveness. Then, the competitors respond with their own innovation due to the increase of competitive pressure from the front-runner's innovation. This cycle will increase the competitive pressure in the market, leading to a continuous cycle of innovative activities [55]. Numerous studies have been conducted to provide empirical support for the Red Queen effect. However, extant studies have mainly focused on new product development of one type of innovation [54,55].

In this paper, we will examine the effect of continuous incremental innovation, scaling, and an introduction of new architectural innovation, VNAND, on firm performance and how it has affected market share and profit leadership in the NAND flash industry. We also examine how the Red Queen effect has influenced the innovation activities of followers, which could explain the necessity to benchmark the architectural design changes of the pioneering firm.

\section{Methodology and Data}

The content analysis processed in this study was performed with the framework suggested by Elo and Kyngas (2008) and Elo et al. (2014) [56,57]. We conducted a content analysis based on inductive reasoning using three steps—-preparation, organization, and reporting—as summarized in Figure 3. 
Prior to the preparation phase, this study started with the research objective and a review of extant studies. During the preparation phase, this study selected the NAND flash memory industry as the case industry in order to study the research question and collect data. Then, for the organizing phase, this study collected data for product development, market share, and profit from multiple sources (mostly from historical announcements of NAND flash manufacturing firms and from independent market research firms) and grouped the collected data. In this way, we interpreted the relationship between firms' innovation activities and their sustainable performances. Finally, the results were compared with conflicting and similar literature, and this theory was built along with improving the trustworthiness of the content analysis.

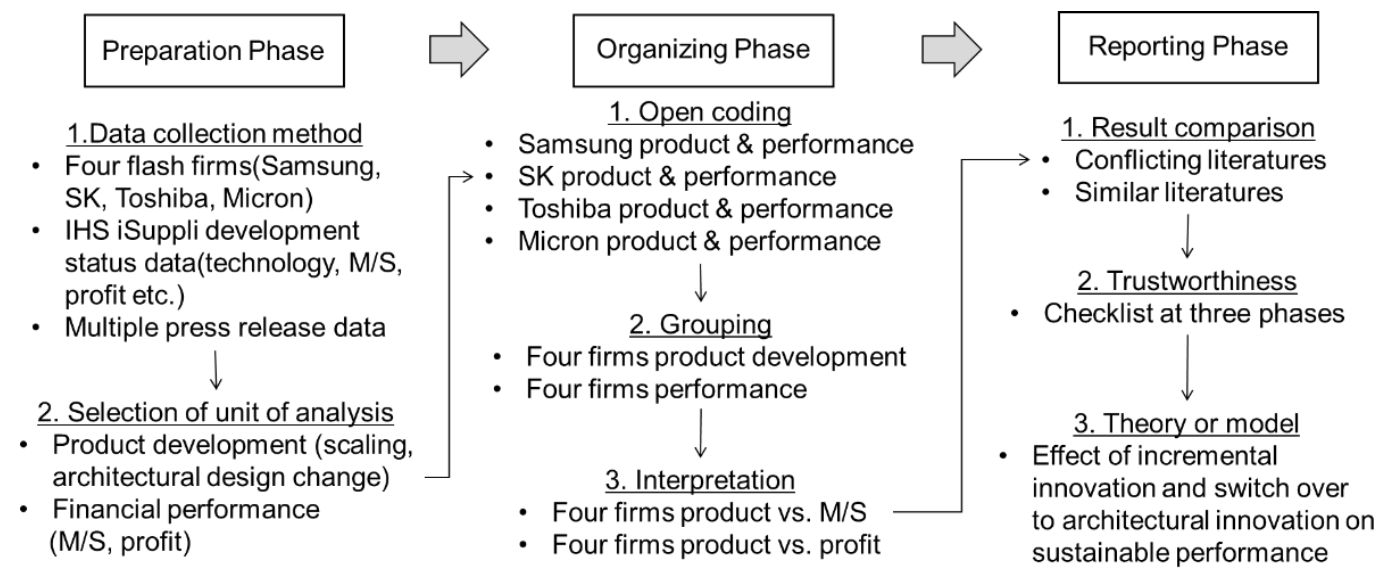

Figure 3. Research methodology of this study based on an inductive content analysis (created from [56]).

\subsection{Preparation Phase}

This study collected data and selected units of analysis during the preparation phase [56]. The quarterly data in this study were accessed and collected from the IHS iSuppli, and the monthly development status data were collected and matched with multiple press releases from each company [5,58-62]. IHS provides a variety of historical and forecast data such as market share, investment, production, and profit. In this way, we extracted the quarterly market share and operating profit margin (OPM) data from 2007 to 2016 for the study. The unit of analysis was selected to be based on monthly product development data (information on scaling or architectural design change) and quarterly financial performance data (market share, profit, OPM). This study focused on the top four NAND flash memory manufacturers, Samsung, SK Hynix, Toshiba, and Micron, since these four companies represent almost $100 \%$ of the total NAND production in the world. This study used the market share data of fabrication plant output revenue-which refers to the total produced NAND flash products by fabrication plant operators-in order to fairly represent the relationship between technological advantage and market share. Hence, the market share of Western Digital and Intel was excluded; their market share was included in Toshiba's and Micron's, respectively, since Toshiba operates Western Digital's fabrication plant and Micron operates Intel's fabrication plant due to the joint development strategy agreed upon by the companies. The market share and the profit of only the NAND flash division were used, and the market share and profit of other divisions in the company were excluded. Also, the quarterly total production of planar NAND and VNAND was gathered to visualize the trend of the total output of the NAND industry between the planar and vertical architectures.

\subsection{Organization Phase}

During the organizing phase, this study conducted open coding, grouping, and interpretation steps [57]. Open coding means that notes and headings are written in the text while reading it; this study conducted open coding by reading and writing product development and performance data for four firms in the flash industry. After open coding, this study conducted grouping with the aim 
of reducing the number of collected data categories by collapsing those that are similar or dissimilar into broader higher-order categories [56]. Thus product developments, as well as performance data, are grouped together for the four firms in the flash industry. As the final step in the organization phase, grouped data are interpreted by linking product development data with performance data. The historical monthly product development data of the four major NAND memory manufacturers were matched with their quarterly profit and market share data to show how the development of the next scaling node affects the firm's sustainable performance. We created a graph of the time vs. market share or profit ranking and plotted the developmental histories of the different scaling nodes for each NAND flash manufacturer, which are the outcome of continuous incremental innovation in each firm. OPM data were refined to represent the ranking of each firm since the ranking of NAND flash manufactures makes it easy to determine profit leadership, since the amount of OPMs for each quarter can be negative in this competitive industry. In order to compare the profit performance of each company in terms of making a profit, we created a table of time vs. each company's positive or negative profit time period. The graph of the total output of planar vs. vertical NAND was created to visualize the dominant design changes of products in the NAND flash industry.

In addition, a Mann-Whitney U test was performed by Minitab between the first and second leaders in terms of market share and profit values to determine the statistical meaning of the results and compensate for the weakness of content data. This is a very useful non-parametric test developed by Mann and Whitney (1947) to find the significance of the difference between two independent groups when the distribution is asymmetrical or the number of samples is small. The proposed model is outlined in the discussion.

\subsection{Reporting Phase and Trustworthiness}

During the reporting phase, the results were compared with conflicting and similar literature. As Elo et al. (2014) [57] indicated, the trustworthiness of content analysis is improved by maintaining a checklist for content analysis at each phase of preparation, organizing, and reporting. Specifically, the data collection method, sampling strategy, and unit of analysis are checked during the preparation phase. Categorization, interpretation, and representativeness are questioned and checked during the organization phase. The reported results and analytical processes are checked in the reporting phase. Finally, a theory was built by focusing on the effects of continuous incremental innovation and the switch-over to architectural innovation on sustainable performance.

\section{Results and Discussion}

\subsection{The Effect of Innovation Activities in Terms of Market Share}

Figure 4 shows the trend of changes in the market shares of NAND flash companies and their relationships with continuous scaling and architectural innovation activities. The $2 \mathrm{D}$ rectangles in Figure 4 represent the development of different nodes in planar scaling, and the 3D cubes represent the development of different numbers of vertical layers. We can identify the exact month of market entry for the innovative nodes of each company by examining press releases from each company. However, Figure 4 shows only quarterly results since we need to match monthly innovation data with quarterly market share and OPM data. In 2007, Samsung's market share was the highest, almost 50\%, while Toshiba had about 30\%, SK Hynix had $15 \%$, and Micron had a market share of about $5 \%$. However, the market share of Samsung, the technological pioneer, decreased because Samsung could not increase its technology gap with other companies after 2012 even though Samsung tried to achieve a constantly innovative scale for its node from $5 \mathrm{X}$ to $1 \mathrm{X}$ (X represents the different number of each company's implementation size). Toshiba and Micron became technological leaders for the $4 \mathrm{X}$ and $3 \mathrm{X}$ nodes, respectively; however, Samsung was able to introduce a $2 \mathrm{Xnm}$ device faster than any of its competitors. This suggests that the competition became intense in the NAND flash industry, and the Red Queen effect might have been introduced into the industry under a competency trap. Samsung lost its market 
leader position in the first quarter of 2012. Since then, the development of the next generation scale devices of NAND flash has become more difficult (also for $16 \mathrm{~nm}$ devices).

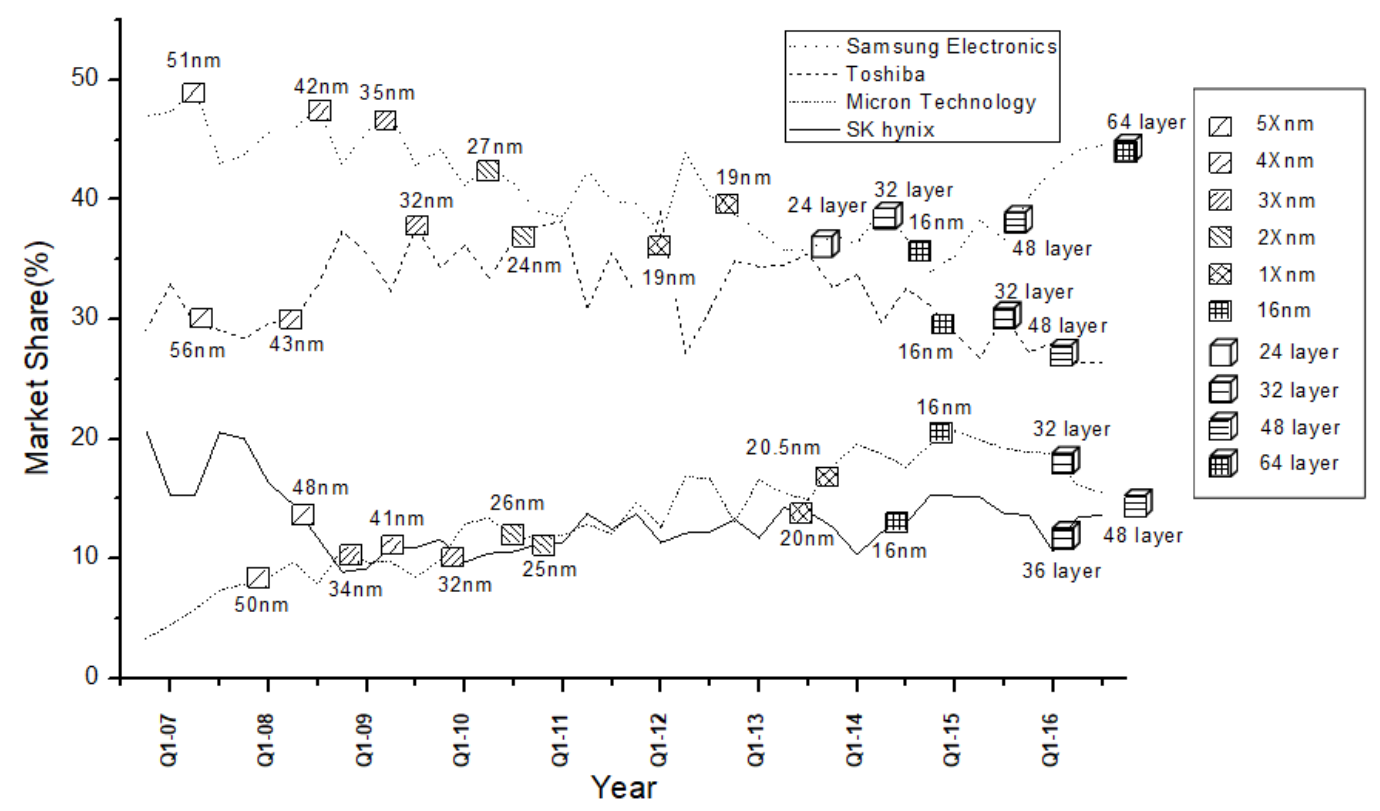

Figure 4. Market share vs companies' scaling innovations and architectural design changes (analyzed and created with data from [5] and the companies' historical data [58-62]).

SK Hynix, who possessed the least advanced 5X to 3X technology, was able to develop faster than any other NAND flash firm due to the competitors' concentration on R\&D activity for vertical NAND to overcome scaling innovations after 1X planar NAND. After the $19 \mathrm{~nm}$ NAND flash device, Samsung began to develop VNAND flash in order to overcome the difficulty of developing and scaling the planar device. In 2011, the roadmap of Samsung did not include a plan for a $19 \mathrm{~nm}$ device. Samsung attempted to develop a $16 \mathrm{~nm}$ device to continue its 2D planar innovation activities [63]. However, somehow, Samsung was not able to produce a $16 \mathrm{~nm}$ device successfully, so they had to step back and produce a $19 \mathrm{~nm}$ device at the end of 2012; this was slower than Toshiba, who were able to produce a $19 \mathrm{~nm}$ device in early 2012. The memory industry is very competitive, so a game of chicken took place in the memory industry from 2008 to 2012. Some memory companies such as Qimonda, Numoyx, and Elpida went out of business despite their innovation efforts as they could not overcome the Red Queen effect during the chicken game. In the planar NAND flash industry, Samsung was able to regain technological leadership by introducing a $2 \mathrm{X} \mathrm{nm}$ device faster than any of its competitors. However, their failure to develop a $16 \mathrm{~nm}$ device pushed them to plan for alternatives and avoid the Red Queen effect. The introduction of VNAND in 2013 means that Samsung developed VNAND starting around 2011, probably when they sensed that the development of a $16 \mathrm{~nm}$ or smaller architecture was very difficult. Samsung, as the technology and market leader, was eager to continue their innovation activities and regain its technological leadership position. Consequently, Samsung was able to focus its resources on developing both planar and vertical NAND at the same time and thereby transformed their methods of development [64].

When the development time increased for $1 \mathrm{X} \mathrm{nm}$, Samsung realized that the complexity of technology and the market was huge and, therefore, also realized that its technology and market leadership were in danger because the continuous incremental innovation of planar scaling was becoming more difficult. Consequently, Samsung developed a new design with different architecture, which gave them success in terms of market share.

Table 2 shows the technological gap of planar devices among NAND flash manufacturers in terms of device generations in chronological order. Table 2 shows the gap by months while Figure 4 uses 
quarters as its unit of time. The pioneer with the fastest development of the current node is set to 0 and the competitors who followed that node are illustrated in terms of the months they took to develop the same scaling nodes. The results show that the technology gap between the market pioneer and second leader was not significant before introducing VNAND. In fact, Toshiba was able to develop the next node device two times before Samsung out of a total of six times in planar NAND flash development. The other two competitors were able to develop faster than Samsung once each. Additionally, the technological gap between the pioneer and the last follower became smaller. For $5 \mathrm{X}$ nm devices, the technological gap between the pioneer and the last follower was 14 months; however, for $16 \mathrm{~nm}$, the technological gap was reduced to 6 months. Table 2 shows that the technological gap between the leader and the follower has become smaller. After VNAND development, Samsung was able to regain its position as a technological leader and all other followers started to develop VNAND products.

Table 2. Technological gap among NAND flash companies in terms of nodes (month) (created with data from [5] and the companies' historical data [58-62]).

\begin{tabular}{ccccccc}
\hline Nodes & Technology Leader & Samsung & Toshiba & Micron & SK Hynix & Gap between 1st and 2nd \\
\hline $5 \times \mathrm{nm}$ & Samsung & 0 & 1 & 8 & 14 & 1 month \\
\hline $4 \mathrm{X} \mathrm{nm}$ & Toshiba & 4 & 0 & N/A & 13 & 4 month \\
\hline $3 \times \mathrm{nm}$ & Micron & 4 & 7 & 0 & 13 & 4 month \\
\hline $2 \mathrm{X} \mathrm{nm}$ & Samsung & 0 & 4 & 2 & 4 & 2 month \\
\hline $1 \mathrm{X} \mathrm{nm}$ & Toshiba & 8 & 0 & 19 & 17 & 8 month \\
\hline $16 \mathrm{~nm}$ & SK Hynix & 2 & 5 & 6 & 0 & 2 month \\
\hline 24 layer & Samsung & 0 & N/A & N/A & N/A & N/A \\
\hline 32 layer & Samsung & 0 & 15 & 20 & 20 & 15 month \\
\hline 48 layer & Samsung & 0 & 5 & N/A & 16 & 5 month \\
\hline 64 layer & Samsung & 0 & N/A & N/A & N/A & N/A
\end{tabular}

The Mann-Whitney $\mathrm{U}$ test shows that the $p$-value between Samsung and Toshiba in terms of market share is 0.0000 , which suggests we can reject the null hypothesis of the leading firm's market share is same as the following firm's market share. Therefore, in terms of market share, the leading firm has sustainable market share leadership.

\subsection{The Effect of Innovation Activities in Terms of Profit}

Figure 5 shows the rankings of profits among NAND flash manufacturers in terms of their different product generations. The $2 \mathrm{D}$ and $3 \mathrm{D}$ expression use the same notation as Figure 4; however, the OPM data were refined to represent the ranking of each firm. Samsung generally shows the highest OPM. From 2007 to 2011, Samsung lost its position as a profit leader twice. However, since the fourth quarter of 2012, when the technology gap between Samsung and other companies was the lowest (as shown in Section 4.1), Toshiba took the profit leader position for ten consecutive quarters. This phenomenon can be explained by Toshiba's technological advantage with its $19 \mathrm{~nm}$ device, and by Samsung's heavy investment in VNAND flash technology during that period. For 24 layered VNAND flash, Samsung was not able to make a reasonable profit compared to planar NAND flash because constructing a fabrication plant for the VNAND flash production environment was costly, and Samsung took time to recover from this heavy investment. Samsung was able to make a reasonable profit after the development of 32 layered VNAND in 2015. Initially, the performance and cost advantage of planar NAND flash was higher; however, as VNAND flash technology showed innovation in terms of OPM, the pioneer, Samsung, was able to enjoy the advantage of the architectural design change from planar to vertical NAND flash technology. Therefore, after the second quarter of 2015, Samsung regained the title of the most profitable firm in the NAND flash industry by regaining market and profit leadership with the help of advances in VNAND flash technology. Other competitors started to develop VNAND flash 
technology, following Samsung. These competitors had to invest heavily in VNAND flash technology, which decreased their OPM for a period of time after starting the development of VNAND.

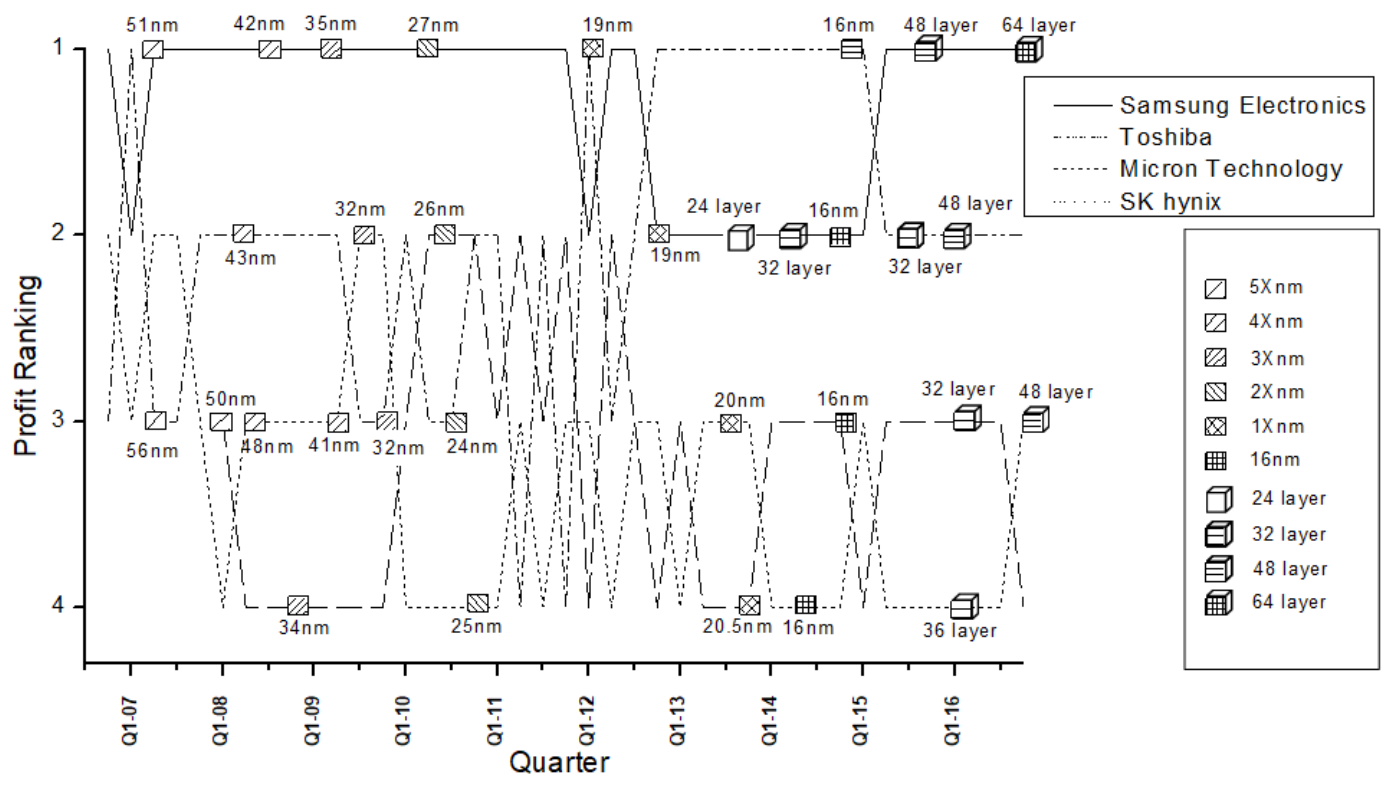

Figure 5. Operating profit margin (OPM) vs. the companies' historical roadmaps in the NAND industry (analyzed and created with data from [5] and the companies' historical data [58-62]).

Figure 5 shows many changes for the firms that ranked third and fourth in profits. The ranking of the profits of the firms varied due to the firms' choices of different strategies for investment, ramping-up timing, and operations. However, for the NAND flash industry, it is notable that NAND flash chips, which are mass-produced after successful R\&D stages, are difficult to differentiate from the products of other firms; the main goal of NAND flash manufactures is to produce more bits in a restricted area of $300 \mathrm{~nm}$ wafers with greater quality and a lower price through technology innovation via continuous scaling innovation. Therefore, the successful scaling of a device that enhances its value-more bits per wafer-is very important for the NAND flash industry.

Table 3 shows the OPM of NAND flash manufacturers from 2007 to 2016 in terms of positive or negative profit. Samsung, the market and technology leader, only showed a negative profit quarter three times from the third quarter of 2008 to the first quarter of 2009 [5]. This is much less common than the 7 times negative profits for the second leader, Toshiba; the 10 times for Micron; and the 14 times for SK Hynix. All three negative profits of Samsung derived from a game of chicken in the memory industry-a price war where the company who is afraid to reduce production due to its deficits would be kicked out of the industry. Samsung was able to remain sustainable in the NAND flash market and was able to make a greater profit than their rivals. During this game of chicken, other companies had more negative profit quarters then Samsung: six times for Toshiba, and eight times each for Micron and SK Hynix. 
Table 3. OPM data (white $=$ positive profit grey $=$ negative profit $)$ created with data from [5] .

\begin{tabular}{|c|c|c|c|c|c|c|c|c|c|c|c|c|}
\hline \multicolumn{2}{|c|}{ Technology Ranking } & 2007 & 2008 & 2009 & 2010 & 2011 & 2012 & 2013 & 2014 & 2015 & 2016 & Total-Profit \\
\hline \#1 Samsung & OPM & & & & & & & & & & & 3 \\
\hline \#2 Toshiba & OPM & & & & & & & & & & & 7 \\
\hline \#3 Micron & OPM & $\mathrm{N} / \mathrm{A}$ & & & & & & & & & & 10 \\
\hline \#4 SK Hynix & OPM & & & & & & & & & & & 14 \\
\hline
\end{tabular}


Then, after 2014, the delayed development of the next-generation device, VNAND flash, which was the result of an architectural design change, led Micron and SK Hynix to produce fewer NAND flash chips per wafer, which led to an increase of the manufacturing costs for NAND flash memory. Trailing behind in architectural design changes yielded two and five negative profit quarters for Micron and SK Hynix, respectively, where they were not able to enjoy the benefits of successful architectural innovation.

A Mann-Whitney U test shows that the $p$-value between Samsung and Toshiba in terms of their profits is 0.0002 which suggests that we can reject the null hypothesis of the leading firm's profit ranking is same as the following firm's profit ranking. Therefore, in terms of profit, the leading firm has the most sustainable profit leadership.

As shown in Figure 6, the output of VNAND flash was expected to exceed the output of planar NAND flash in the year 2017 to become the dominant design. The architectural innovation of VNAND flash started by Samsung was able to outpace its competitors, and to exceed the technological advantage of planar NAND flash was risky. However, after 2017, the strategy of architectural design change rewarded Samsung's efforts to be competitive in the industry, and VNAND flash became the dominantly produced NAND flash type; the followers had to benchmark Samsung's new VNAND product development to remain relevant and successfully surpass the competition.

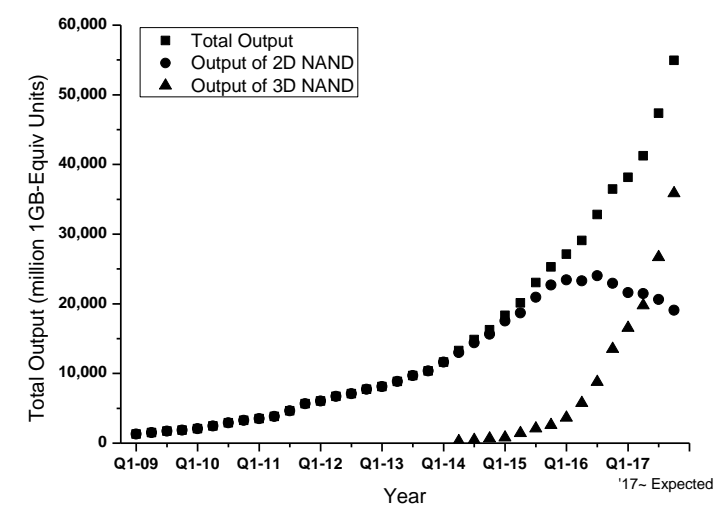

Figure 6. Output vs. year in the NAND flash industry (created with data from [5]).

In order to consider other positive factors to a firm's sustainability, Table 4 was created and the yearly factors of four companies are compared [5]. Table 4a shows the capex (capital expenditure) of the four companies. This factor is widely used to indicate the investment of semiconductor companies. In the semiconductor industry, the investment is mainly used to build semiconductor fabrication plants and to purchase manufacturing equipment. Therefore, capex is somewhat related to the revenue of the companies, Table $4 \mathrm{~b}$, or the production capacity and GB production, Table $4 \mathrm{c}$ and d, respectively. However, it is hard to relate these factors to the technological leadership or the market and profit leadership of the company since the NAND flash products are very hard to differentiate among firms. In terms of production, as shown in Table $4 \mathrm{c}, \mathrm{d}$, Toshiba was able to produce more wafers and more GB than Samsung from 2012 to 2016 and 2010 to 2015, respectively; however, during that period of time, the revenue was better for Samsung, as shown in Table 4b. Usually, the ASP (average selling price) is set in the market and manufacturers have a hard time increasing revenue or profit. Therefore, revenue per wafer, which is defined by the ratio of the number in Table $4 \mathrm{~b}$ to the number in Table $4 \mathrm{c}$, is the most important efficiency factor, which is shown in Table 4e. Samsung was able to maintain the highest revenue per wafer in six out of a total of nine years, which is higher than competitors (twice for Toshiba, once for Micron). This indicates the technological and market leader was able to produce more revenue per wafer. Therefore, in terms of market share and profit, increasing the total revenue per wafer through technological innovation is more important than producing more wafers, Table 4c, or producing more GB by investments to increase capacity, Table $4 \mathrm{~d}$. Generally, one successful next-generation product by continuous scaling and stacking leads to $20 \%$ more chips per wafer, which 
increases the efficiency of wafer for the innovating firm. Therefore, the investment or production increase activities with capex, Table $4 a$, might affect the factors of Table $4 b, c$, and d; however, it does not affect sustainable profit if the activities do not involve the technological innovation of continuous scaling and stacking. For NAND flash manufacturers, the important factor for sustainability is not how much total wafer or total GB that a firm produces; however, it depends on the efficiency of the revenue per wafer: how much value per wafer can be produced compared to the competitors through technological innovation.

Table 4. Comparative factors of four companies of the study (a) capex (millions of dollars), (b) revenue (millions of dollars), (c) total wafer production (thousands of wafers), (d) total GB production (millions of units), (e) revenue / thousands of wafer (millions of dollars), (analyzed and created with data from [5]).

\begin{tabular}{|c|c|c|c|c|c|c|c|c|c|c|c|}
\hline (a) & $\begin{array}{c}\text { Capex } \\
\text { (millions of dollars) }\end{array}$ & 2007 & 2008 & 2009 & 2010 & 2011 & 2012 & 2013 & 2014 & 2015 & 2016 \\
\hline & Samsung & 3500 & 3300 & 1100 & 3700 & 3000 & 3500 & 4000 & 2900 & 3300 & 4600 \\
\hline & Toshiba & 3500 & 3700 & 1000 & 2600 & 3500 & 2400 & 2150 & 2500 & 3000 & 3400 \\
\hline & Micron & 2300 & 2300 & 400 & 700 & 1800 & 1100 & 950 & 1300 & 1500 & 2500 \\
\hline & SK Hynix & 950 & 500 & 150 & 800 & 750 & 2000 & 1000 & 1100 & 1300 & 1600 \\
\hline \multirow[t]{5}{*}{ (b) } & $\begin{array}{c}\text { Revenue } \\
\text { (millions of dollars) }\end{array}$ & & & & & & & & & & \\
\hline & Samsung & 5864 & 4960 & 5419 & 7283 & 7842 & 7504 & 8700 & 9084 & 9826 & \\
\hline & Toshiba & 3832 & 3459 & 4339 & 6393 & 6140 & 6152 & 8196 & 7899 & 7399 & \\
\hline & Micron & 853 & 984 & 1161 & 2474 & 3349 & 3400 & 3858 & 4691 & 5142 & \\
\hline & SK Hynix & 2369 & 1450 & 1343 & 1864 & 2504 & 2295 & 3150 & 3185 & 3773 & \\
\hline \multirow[t]{5}{*}{ (c) } & $\begin{array}{c}\text { Total wafer } \\
\text { production } \\
\text { (thousands of wafers) }\end{array}$ & & & & & & & & & & \\
\hline & Samsung & 2482 & 3733 & 4081 & 3884 & 4166 & 3781 & 3562 & 3636 & 4336 & 4720 \\
\hline & Toshiba & 1785 & 2870 & 2349 & 3093 & 3767 & 3977 & 4022 & 4662 & 5925 & 6617 \\
\hline & Micron & 883 & 1296 & 1104 & 1230 & 1489 & 2246 & 2276 & 2810 & 3045 & 3268 \\
\hline & SK Hynix & 1740 & 1551 & 739 & 980 & 1166 & 1656 & 1758 & 2123 & 2399 & 2621 \\
\hline \multirow[t]{5}{*}{ (d) } & $\begin{array}{l}\text { Total GB production } \\
\text { (millions of units) }\end{array}$ & & & & & & & & & & \\
\hline & Samsung & 805 & 1867 & 2405 & 3931 & 5810 & 7883 & 11,747 & 18,186 & 29,317 & 48,006 \\
\hline & Toshiba & 575 & 1457 & 2261 & 4278 & 7051 & 12,590 & 17,785 & 23,443 & 32,148 & 46,086 \\
\hline & Micron & 147 & 599 & 1090 & 1794 & 3706 & 5235 & 6492 & 10,810 & 13,641 & 15,934 \\
\hline & SK Hynix & 363 & 489 & 431 & 823 & 2027 & 2973 & 4228 & 6876 & 11,681 & 16,949 \\
\hline \multirow[t]{5}{*}{ (e) } & $\begin{array}{l}\text { Revenue per wafer } \\
\text { (millions of dollars) }\end{array}$ & & & & & & & & & & \\
\hline & Samsung & 2.4 & 1.3 & 1.3 & 1.9 & 1.9 & 2.0 & 2.4 & 2.5 & 2.3 & \\
\hline & Toshiba & 2.1 & 1.2 & 1.8 & 2.1 & 1.6 & 1.5 & 2.0 & 1.7 & 1.2 & \\
\hline & Micron & 1.0 & 0.8 & 1.1 & 2.0 & 2.2 & 1.5 & 1.7 & 1.7 & 1.7 & \\
\hline & SK Hynix & 1.4 & 0.9 & 1.8 & 1.9 & 2.1 & 1.4 & 1.8 & 1.5 & 1.6 & \\
\hline
\end{tabular}

Staying sustainable and competitive through continuous incremental innovation is critical for the firms' sustainable performance in the market where competition is very intense. As verified by Samsung, architectural innovation is also effective to reframe an old design to the new one and help a firm to reset the technological lifecycle and continue their sustainable growth in the industry, as discussed in Sections 4.1 and 4.2 The results suggest that the technology pioneer that adopts successful 
architectural innovation with different designs faster than the competitors can continuously enjoy the benefits from it by maintaining itself as a technological pioneer in the VNAND industry.

\section{Conclusions and Implications}

This study offers empirical insights for NAND flash manufacturers to regard continuous incremental innovation as one of the most important types of innovation in the NAND flash industry. Moreover, understanding the right entry time to adopt a new design, architectural innovation, is useful for firms for their sustainability, as technological pioneers have suggested. Samsung experienced the limitations of the planar scaling of NAND flash devices and had difficulty in developing it, so they decided to conduct architectural design change in order to reduce technology complexity. This decision gave Samsung a chance to become the technology leader again in the NAND flash industry. The concept of continuous incremental innovation and architectural innovation applies to the memory industry, and Samsung's efforts to develop next-generation products through continuous scaling and architectural change, to be more competitive than its competitors, helped Samsung regain its market share and profitable position as a sustainable market leader to becoming the most profitable firm in the NAND flash industry. Also, its followers then tried to benchmark the pioneer in order to avoid the Red Queen effect, not only for 2D planar scaling but also to develop VNAND.

The history of the flash memory industry is dynamic, having first been led by NOR flash, before becoming suddenly dominated by NAND flash due to the emergence of mobile electronics applications. The competitors of technology pioneers were able to pursue the technological development of a planar NAND flash and almost overcame the success of the pioneer. However, the technology pioneer managed to return with VNAND flash technology and was able to regain the benefits of being the technology and market leader. The most important factor in determining a firm's ability to be able to dominate in the NAND flash industry is "continuous incremental innovation and timely introduction of architectural design change", which provides the ability for firms to evolve and gain sustainability in the NAND flash industry.

This study provides several new theoretical implications compared to extant research. First, the firms' innovative behaviors are generally correlated with improving the firms' financial performance $[1,2]$. However, the research associating types of innovation with firm performance is limited. Further, extant research focuses more on understanding the effects of radical or incremental innovation of new products when correlating the effect of technological innovation on the firms' performance [19-26]. This study identified that the continuity of incremental innovation, scaling, is important to improving the firms' sustainable performance based on the findings from the NAND flash industry. In addition, the firms' ability to introduce architectural innovation just on time is more important in an industry where architectural change is critical to survive and maintain leadership in the market. This study also links different types of innovation to the firms' sustainable performance.

Second, the extant research suggests that the effects of innovation on market entry strategies are unresolved [64,65], while the determinants and performance of entry strategies are heavily addressed after a discussion of first-mover advantage is initiated [66]. This study identified that architectural innovation could affect the established frame and result in different entry strategies among competitors, based on the findings of the NAND flash industry. Samsung is a good example of using a product leader strategy by introducing VNAND architectures for the first time; the rest of the market entrants became fast followers to exploit this new architecture. This study provides additional insight into how to relate the phenomenon of innovation to market entry strategies.

This study has practical implications for the managers of high-tech firms. First, technological leadership is important, whether there is an established frame, dominant design, or change, for two reasons. Technological leadership, which can be rewarded by either continuous incremental innovation or new architectural innovation, gives the firm sustainable leadership in its market share and profit margins, and a technological leader has better resilience during periods where there is a market or 
technological crisis in the industry; increasing comparative advantage with respect to competitors increases the sustainability of a firm.

Second, the dominant design change of architectural innovation does not interrupt the loop of continuity of innovation. In fact, it lets a firm abandon old and outdated established frames and set another innovation with the possibility of continuous innovation when the complexity of technology and the market is great. Samsung's decision to engage in VNAND flash development was risky since other firms were continuously trying to develop the current design. However, knowing that the development of planar technology was becoming more difficult and that competitors were following up on the technology of the current design, the technology pioneer chose to focus on VNAND flash development, which helped it to gain an advantage as a technological leader and also regain market and profit leadership. These activities of technological leaders might show others in the industry that they are in a competency trap and help them escape from this trap. Leaders are the first to know the limitations of the current design of the technology and they have resources to test different innovation activities at the same time [67]. Therefore, all of the main competitors, including newcomers from China, in the NAND flash industry are currently developing VNAND products, and the total output of VNAND exceeds that of planar NAND flash.

Despite its efforts to consider everything, this study has some limitations. First, even though other activities of incremental innovation are already somewhat included in a firm's performance, this study only considers continuous scaling and the architectural innovation of VNAND in the NAND flash industry, so more studies are required to generalize our findings. Secondly, due to the dynamic changes in the industry, our study only collected data from 2007 to 2016 . Future studies on the relationship between continuous incremental innovation and architectural innovation can improve our findings. Third, further research on other industries with architectural innovation would help expand our understanding of technological innovation and the effects of architectural innovation on a firm's sustainability. Fourth, this study focused on investigating the firms' financial performance, such as market share or profit. Since technological innovation is highly correlated with technological knowledge, such as published papers or issued patents, further investigation of technological knowledge could give additional insights into the effect of innovation on the firms' sustainable performance. For our next research topic, we would like to investigate the transactional period from NOR to NAND flash as this change is also considered an architectural innovation since the structure of the device was changed from a parallel accessible NOR device to a slow sequentially-accessible NAND device, which might help us understand how and where the market experiences modular innovation.

Author Contributions: Conceptualization, H.K.; methodology, C.P.; data curation, H.K.; analysis, H.K; theoretical implications; C.P.; writing —original draft preparation, H.K.; writing—review and editing, H.L.; supervision, H.L.

Funding: This work was partially supported by the Institute of Information and communications Technology Promotion (IITP) grant funded by the Korean government (MSIT) (No.2019-0-01547) and the National Research Foundation of Korea (NRF) grant funded by the Korean government (MSIT) (No.2018R1D1A1B07050139).

Conflicts of Interest: The authors declare no conflict of interest.

\section{References}

1. Guan, H.; Zhang, Z.; Zhao, A.; Jia, J.; Guan, S. Research on Innovation Behavior and Performance of New Generation Entrepreneur Based on Grounded Theory. Sustainability 2019, 11, 2883. [CrossRef]

2. Gimenez, J.; Madrid-Guijarro, A.; Duréndez, A. Competitive Capabilities for the Innovation and Performance of Spanish Construction Companies. Sustainability 2019, 11, 5475. [CrossRef]

3. Lawton, G. Improved flash memory grows in popularity. Computer 2006, 39, 16-18. [CrossRef]

4. Wong, G. Market and applications for NAND flash memories. In Inside NAND Flash Memories; Springer: Dordrecht, The Netherlands, 2010; pp. 1-18.

5. IHS Technology. Available online: https://technology.ihs.com/ (accessed on 25 October 2019).

6. Kang, J.H. A Study of DRAM Industry. Master's Thesis, Management Studies, MIT, Cambridge, MA, USA, 2010. 
7. Kim, K.N. Plenary Talk Future Silicon Technology. In Proceedings of the ESSCIRC, Bordeaux, France, 17-21 September 2012; IEEE: Piscataway, NJ, USA; pp. 1-6.

8. Mack, C.A. Using learning curve theory to redefine Moore's Law. Solid State Technol. 2003, 46, 51-58.

9. Freeman, C. Critical survey: The economics of technical change. Camb. J. Econ. 1994, 18, 463-514. [CrossRef]

10. Sen, F.K.; Egelhoff, W.G. Innovative capabilities of a firm and the use of technical alliances. IEEE Trans. Eng. Manag. 2000, 47, 174-183. [CrossRef]

11. Henderson, R.; Clark, K. Architectural Innovation: The Reconfiguration of Existing Product Technologies and the Failure of Established Firms. Adm. Sci. Q. 1990, 35, 9-30. [CrossRef]

12. Christensen, C.M. Exploring the Limits of the Technology S-Curve, Part I: Component Technologies. Prod. Oper. Manag. 1992, 1, 334-357. [CrossRef]

13. Lee, S.M.; Trimi, S. Innovation for creating a smart future. J. Innov. Knowl. 2018, 3, 1-8. [CrossRef]

14. Shaukat, S.; Nawaz, M.S.; Naz, S. Effects of innovation types on firm performance: An empirical study on Pakistan's manufacturing sector. Pak. J. Commer. Soc. Sci. (PJCSS) 2013, 7, 243-262.

15. Organisation for Economic Co-operation (OECD). Oslo Manual: Proposed Guidelines for Collecting and Interpreting Technological Innovation Data; OECD: Paris, France, 2005.

16. Kim, H.S.; Lee, H.S. Architecture innovation in the DRAM industry: How it affects firms' sustainable competence. Solid State Technol. 2017, 60, 12-16.

17. Seebode, D.; Jeanrenaud, S.; Bessant, J. Managing innovation for sustainability. R D Manag. 2012, 42, $195-206$. [CrossRef]

18. Roy, R.; Miller, J. Miniaturization of image sensors: The role of innovations in complementary technologies in overcoming technological trade-offs associated with product innovation. J. Eng. Technol. Manag. 2017, 44, 58-69. [CrossRef]

19. Bolton, M.K. Organizational innovation and substandard performance. Organ. Sci. 1993, 4, 57-75. [CrossRef]

20. Blundell, R.; Griffith, R.; Van Reenen, J. Market Share, Market Value and Innovation in a Panel of British Manufacturing Firms. Rev. Econ. Stud. 1999, 66, 529-554. [CrossRef]

21. Lee, H.; Smith, K.; Grimm, C.; Schomburg, A. Timing, Order and Durability of New Product Advantages with Imitation. Strateg. Manag. J. 2000, 21, 23-30. [CrossRef]

22. Sharma, A.; Nelson, L. Linking Product Development Outcomes to Market Valuation of the Firm: The Case of the U.S. Pharmaceutical Industry. J. Acad. Mark. Sci. 2004, 21, 297-308. [CrossRef]

23. Sorescu, A.B.; Spanjol, J. Innovation's effect on firm value and risk: Insights from consumer packaged goods. J. Mark. 2008, 72, 114-132. [CrossRef]

24. Zhou, J.; Jiao, H.; Li, J. Providing Appropriate Technology for Emerging Markets: Case Study on China's Solar Thermal Industry. Sustainability 2017, 9, 178. [CrossRef]

25. Han, S.; Cui, W.; Chen, J.; Fu, Y. Female CEOs and Corporate Innovation Behaviors-Research on the Regulating Effect of Gender Culture. Sustainability 2019, 11, 682. [CrossRef]

26. Srinivasan, S.; Pauwels, K.; Silva-Risso, J.; Hanssens, D. Product Innovations, Advertising Spending and Stock Returns. Mark. Sci. Inst. Rep. 2006.

27. Banbury, C.M.; Mitchell, W. The effect of introducing important incremental innovations on market share and business survival. Strateg. Manag. J. 1995, 16, 161-182. [CrossRef]

28. Satoh, S.; Hagiwara, H.; Tanzawa, T.; Takeuchi, K.; Shirota, R. A novel isolation-scaling technology for NAND EEPROMs with the minimized program disturbance. In Proceedings of the IEDM Technical Digest, Washington, DC, USA, 10 December 1997; Banbury, C.M., Mitchell, W., Eds.; IEEE: Piscataway, NJ, USA; pp. 291-294.

29. Utterback, J.M.; Abernathy, W.J. A Dynamic Model of Product and Process Innovation. Omega 1975, 3, 639-656. [CrossRef]

30. Utterback, J. Mastering the Dynamics of Innovation; Harvard Business School Press: Boston, MA, USA, 1994.

31. Brem, A.; Nylund, P.A.; Schuster, G. Innovation and de facto standardization: The influence of dominant design on innovative performance, radical innovation, and process innovation. Technovation 2016, 50-51, 79-88. [CrossRef]

32. Swann, G. The Economics of Standardization: Final Report for Standards and Technical Regulations Directorate; Manchester Business School, Department of Trade and Industry: Manchester, UK, 2000. 
33. Woo, S.; Jang, P.; Kim, Y. Effects of intellectual property rights and patented knowledge in innovation and industry value added: A multinational empirical analysis of different industries. Technovation 2015, 43-44, 49-63. [CrossRef]

34. Blind, K. The Impact of Standardization and Standards on Innovation; NESTA Work. Pap. Ser. 13/15; University of Manchester: Manchester, UK, 2013; pp. 1-32.

35. Soh, P.H. Network patterns and competitive advantage before the emergence of a dominant design. Strateg. Manag. J. 2010, 31, 438-461. [CrossRef]

36. Luo, J. A simulation-based method to evaluate the impact of product architecture on product evolvability. Res. Eng. Des. 2015, 26, 355-371. [CrossRef]

37. Geroski, P.A.; Toker, S. The turnover of market leaders in UK manufacturing industry, 1979-1986. Int. J. Ind. Organ. 1996, 14, 141-158. [CrossRef]

38. Crane, A. In the company of spies: When competitive intelligence gathering becomes industrial espionage. Bus. Horiz. 2005, 48, 233-240. [CrossRef]

39. Fosfuri, A.; Giarrantana, M.S. Masters of war: rivals' product innovation and new advertising in mature product markets. Manag. Sci. 2009, 55, 181-191. [CrossRef]

40. Coad, A.; Teruel, M. Inter-firm rivalry and firm growth is there any evidence of direct competition between firms. Ind. Corp. Chang. 2013, 22, 397-425. [CrossRef]

41. Boone, J.; Van Ours, J.C.; Van der Weil, H. How (Not.) to Measure Competition; CEPR Discussion Paper 6275; Centre for Economic Policy Research: London, UK, 2007.

42. Mack, C.A. Fifty years of Moore's law. Trans. Semicond. Manuf. 2011, 24, 202-207. [CrossRef]

43. Smithsonian Institution. Available online: http://smithsonianchips.si.edu/ice/cd/CEICM/section1.pdf (accessed on 27 November 2019).

44. Weber, C.; Yang, J. Organizational Learning and Capital Productivity in Semiconductor Manufacturing. IEEE Trans. Semicond. Manuf. 2014, 27, 316-326. [CrossRef]

45. Camisón-Zornoza, C.; Lapiedra-Alcamí, R.; Segarra-Ciprés, M.; Boronat-Navarro, M.A. Meta-analysis of innovation and organizational size. Organ. Stud. 2004, 25, 331-361. [CrossRef]

46. Hart, S.L.; Dowell, G. A natural-resource-based view of the firm: Fifteen years after. J. Manag. 2011, 37, 1464-1479.

47. Porter, M.E.; Van der Linde, C. Toward a new conception of the environment-competitiveness relationship. J. Econ. Perspect. 1995, 9, 97-118. [CrossRef]

48. Crossan, M.M.; Apaydin, M. A multi-dimensional framework of organizational innovation: A systematic review of the literature. J. Manag. Stud. 2000, 47, 1154-1191. [CrossRef]

49. Damanpour, F. Footnotes to research on management innovation. Organ. Stud. 2014, 35, 1265-1285. [CrossRef]

50. Oura, M.M.; Novaes Zilber, S.; Lopes, E.L. Innovation capacity, international experience and export performance of SMEs in Brazil. Int. Bus. Rev. 2016, 25, 921-932. [CrossRef]

51. Teece, D.J.; Pisano, G.; Shuen, A. Dynamic capabilities and strategic management. Strateg. Manag. J. 1997, 18, 509-533. [CrossRef]

52. Bowen, F.; Rostami, M.; Steel, P. Timing is everything: A meta-analysis of the relationships between organizational performance and innovation. J. Bus. Res. 2010, 63, 1179-1185. [CrossRef]

53. Van Valen, L. A new evolutionary law. Evol. Theory 1973, 1, 1-30.

54. Barnett, W.P.; Hansen, M.T. The Red Queen in organizational evolution. Strateg. Manag. J. 1996, $17,139-157$. [CrossRef]

55. Talay, M.B.; Calantone, R.J.; Voorhees, C.M. Co-evolutionary dynamics of Automotive Competition: Product Innovation, Change, and Market Place Survival. J. Prod. Innov. Manag. 2014, 31, 61-78. [CrossRef]

56. Elo, S.; Kyngas, H. The qualitative content analysis process. J. Adv. Nurs. 2008, 62, 107-115. [CrossRef]

57. Elo, S.; Kääriäinen, M.; Kanste, O.; Pölkki, T.; Utriainen, K.; Kyngäs, H. Qualitative Content Analysis: A Focus on Trustworthiness. SAGE Open 2014, 4,1-10. [CrossRef]

58. Samsung Press Releases. Available online: https://www.samsung.com/semiconductor/insights/?page=1 (accessed on 16 April 2017).

59. Toshiba Press Release. Available online: https://www.toshiba.co.jp/about/press/index.htm (accessed on 16 April 2017). 
60. Micron Press Release. Available online: https://www.micron.com/about/newsroom (accessed on 16 April 2017).

61. SK Hynix Press Release. Available online: http://www.skhynix.com/eng/pr/pressReleaseList.do?offset= (accessed on 16 April 2017).

62. EE Times. Available online: https://www.eetimes.com/ (accessed on 16 November 2019).

63. Techinsight. Available online: https://www.techinsights.com/ (accessed on 17 November 2019).

64. Markides, C.; Sosa, L. Pioneering and First Mover Advantages: The Importance of Business Models. Long Range Plan. 2013, 46, 325-334. [CrossRef]

65. Fosfuri, A.; Lanzolla, G.; Suarez, F.F. Entry-Timing Strategies: The Road Ahead. Long Range Plan. 2013, 46, 300-311. [CrossRef]

66. Lieberman, M.B.; Montgomery, D.B. Fist-mover advantages. Strateg. Manag. J. 1988, 9, 41-58. [CrossRef]

67. Barnett, W.P.; Pontikes, E.G. The Red Queen: History-dependent competition among organizations. Res. Organ. Behav. 2004, 26, 351-371. [CrossRef]

(C) 2019 by the authors. Licensee MDPI, Basel, Switzerland. This article is an open access article distributed under the terms and conditions of the Creative Commons Attribution (CC BY) license (http://creativecommons.org/licenses/by/4.0/). 